\title{
Association analysis of body mass index on ovarian response and pregnancy outcomes during IVF / ICSI treatment: a retrospective study in Southern Han Chinese Women
}

Li Li

Third Affiliated Hospital of Guangzhou Medical College

Yanhong Chen

Third Affiliated Hospital of Guangzhou Medical College

Chengli Zeng

Third Affiliated Hospital of Guangzhou Medical College https://orcid.org/0000-0001-8471-2029

Weilin Ou

Third Affiliated Hospital of Guangzhou Medical College

Zhifeng Lin

Third Affiliated Hospital of Guangzhou Medical College

Weiyan Lin

Third Affiliated Hospital of Guangzhou Medical College

Yangqi Liu

Third Affiliated Hospital of Guangzhou Medical College

Li Ke ( $\square$ keli1221@126.com)

\section{Research article}

Keywords: ovarian response, spontaneous abortion rate, BMI, IVF / ICSI

Posted Date: August 21st, 2019

DOl: https://doi.org/10.21203/rs.2.13315/v1

License: (1) This work is licensed under a Creative Commons Attribution 4.0 International License. Read Full License 


\section{Abstract}

Objectives The purpose of the present study is to evaluate the effect of body mass index (BMI) on cycle characteristics and in vitro fertilization / intracytoplasmic sperm injection (IVF / ICSI) outcomes of a long down-regulation protocol in Southern Han Chinese women. Methods This retrospective, observational study included 5279 infertile women undergoing IVF / ICSI cycle with a long down-regulation protocol. All the patients were divided into four subgroups by the recommended Chinese BMl cut-off points: underweight, BMI $<18.5 \mathrm{~kg} / \mathrm{m} 2$; normal-weight, $18.5 \mathrm{~kg} / \mathrm{m} 2 \leq \mathrm{BMl}<24.0 \mathrm{~kg} / \mathrm{m} 2$; overweight, $24.0 \mathrm{~kg} / \mathrm{m} 2 \leq \mathrm{BMl}<28.0 \mathrm{~kg} / \mathrm{m} 2 ;$ obese, $\mathrm{BMl} \geq 28.0 \mathrm{~kg} / \mathrm{m} 2$. The demographic data and biochemical tests of patients, the parameters related to the ovarian responsiveness to gonadotrophin stimulation, IVF / ICSI treatment characteristics and pregnancy outcomes (clinical pregnancy rate, spontaneous abortion rate and lived birth rate) were compared among BMI categories. Results The overweight and obese infertile patients required more priming gonadotropin, total gonadotropin and longer stimulation duration, and had the lower ovarian sensitivity index (OSI), lower serum progestogen (P) and estrogen (E2) on the day of HCG administration compared with the normal-weight women $(P<0.05)$. The overweight and obese patients had a higher spontaneous abortion rate than women in the normal-weight $(13.59 \%$ vs. $10.28 \%$, OR $=1.40,95 \% \mathrm{Cl}: 1.02-1,90, \mathrm{P}=0.036 ; 17.58 \%$ vs. $10.28 \%, \mathrm{OR}=1.92$, $95 \% \mathrm{Cl}: 1.09-3.36, \mathrm{P}=0.023$, respectively). The overweight and obese patients seemed to have lower clinical pregnancy rate and live birth rate, but the difference was not statistically significant $(P>0.05)$. Conclusion This study provides new epidemiological clues that the elevated BMI might impair ovarian response to gonadotropin stimulation and increase the risk of spontaneous abortion during IVF / ICSI treatment.

\section{Introduction}

Elevated body mass index (BMI), the most common medical condition in women at a reproductive age[1], has rapidly become an important global public health problem[2]. The prevalence of obesity has continued to rise, with the most recent estimate indicating that $35.2 \%$ of men and $40.4 \%$ of women are obese[3]. Overweight and obesity, especially abdominal obesity is known to be associated with an increased risk of a variety of chronic diseases, such as cardiovascular disease (CVD), type 2 diabetes mellitus (T2DM), asthma and cancer[4,5]. Women who become pregnant while obese are at a higher risk of developing pregnancy specific complications, poor neonatal and maternal pregnancy outcomes, such as gestational hypertension, gestational diabetes mellitus, preeclampsia, fetal macrosomia, congenital anomalies, and stillbirths[6-8].

Obesity-related infertility is another critical problem for reproductive age women[9, 10]. In the last decades, the trend of delaying marriage and childbearing has further exacerbated the burden of infertility[11]. As consequence, more and more infertility women are seeking for treatment, assisted reproductive technology (ART) has become an important option for patients with infertility who wish to become pregnant and contributed to the birth of over 5 million live born babies worldwide[12,13]. Over the past decades, with the rapid popularity of ART for infertility treatment, a growing number of babies were born from in vitro fertilization (IVF) or intracytoplasmic sperm injection (ICSI) [14]. Controlled ovarian hyper-stimulation $(\mathrm{COH})$ is a fundamental part and the key to the success and safety of ART, while the gonadotropin-releasing hormone agonist (GnRH-a) long protocol is one of the common regimens for ovarian stimulation[15]. The use of GnRH-a has been found to be associated with a reduction in cancellation rates, an increase in multiple follicular growth, and a potentially better timing of the treatment cycle[16].

The effect of overweight / obesity on IVF / ICSI outcome has been extensively investigated in numerous studies. However, the relationship between overweight / obesity and IVF / ICSI outcome (such as oocyte, embryo quality and pregnancy outcomes) is still inconclusive. In some of the early reports, a significant negative effect was found between raised BMI and pregnancy outcomes[17, 18], whereas others reported no adverse effects[19, 20]. In addition, most of these previous studies was carried out in Caucasian women, as the racial differences in clinical characteristics and infertility frequency, these previous data were not available to be clinical practice in Chinese or Asian populations[21]. 
Furthermore, with the full implementation of the Chinese universal two-child policy, more and more infertile women of childbearing age choose to have two children by ART treatment[5], it is not surprising that an increasing number of women seeking infertility treatment to achieve a pregnancy are overweight or obese[22, 23]. As the low success rate of the ART treatment and the increased incidence of overweight / obese, it is still very important to update the data and explore the various potential factors associated with ART treatment outcome. Respecting these concerns, this study aims to determine the effect of elevated BMI on the cycle characteristics and IVF / ICSI outcomes of a down-regulation GnRH-a long protocol in Southern Han Chinese women.

\section{Materials And Methods}

\subsection{Study design and subjects}

This was a retrospective cohort study of patients undergoing their first IVF / ICSI cycle, using a down-regulation GnRH-a long protocol, in the center for reproductive medicine of The Third Affiliated Hospital of Guangzhou Medical University from August 2012 to November 2017.

Exclusion criteria were: preimplantation genetic diagnosis (PGD), invitro maturation, oocyte or sperm donation, frozen embryo transfer, gestational surrogacy cycles, patients with oophoritic cyst, operation on ovary, ovarian tumor, oophoroma, polycystic ovary syndrome (PCOs), endometriosis, operation on uterus, hysteromyoma, uterine adenoma, uterine tumors, cervical carcinoma, precancerous lesions of uterine cervix, hydrosalpinx, thyroid dysfunction, hypertension, diabetes, and other sever diseases. In total, 5279 patients undergoing their first IVF / ICSI cycle with fresh, autologous embryos were analyzed with age under 35 years old. All the patients were divided into four subgroups by the recommended Chinese BMI cut-off points[24]: underweight, BMI $<18.5 \mathrm{~kg} / \mathrm{m}^{2}$; normal-weight, $18.5 \mathrm{~kg} / \mathrm{m}^{2} \leq \mathrm{BMI}<$ $24 \mathrm{~kg} / \mathrm{m}^{2}$; overweight, $24.0 \mathrm{~kg} / \mathrm{m}^{2} \leq \mathrm{BMI}<28 \mathrm{~kg} / \mathrm{m}^{2}$; and obese, BMI $\geq 28 \mathrm{~kg} / \mathrm{m}^{2}$. Normal-weight patients were used as the reference group for all comparisons.

\subsection{Treatment}

In preparation for pituitary desensitization, all the patients were treated with a standard mid-luteal phase GnRH-a long protocol with Triptorelin (Dipherelin, $3.75 \mathrm{mg}$ Ipsen, Pairs, France) at a dose of $0.1 \mathrm{mg}$ daily.

Once pituitary suppression (the serum concentrations of estradiol (E2) $<50 \mathrm{pg} / \mathrm{mL}$ and endometrial thickness (EMT) $<5 \mathrm{~mm}$ ) was achieved, Recombinant follicle-stimulating hormone ( $\mathrm{rFSH}$; Gonal-F, Serono, Switzerland) was given for ovarian stimulation until the day of human chorionic gonadotrophin (HCG) administration.

The follicular growth was monitored by using transvaginal three-dimensional (3D) ultrasonography, oocyte maturation and ovulation was induced with 10000 IU urinary HCG (u-HCG) or 250 ug recombinant HCG (r-HCG; Ovitrelle, Merck KCaA, Germany) injection when the number of leading follicles (> $18 \mathrm{~mm}$ in diameter) was 2 or more. Oocyte retrieval was performed by transvaginal ultrasound 34-36 hours after injection of HCG and followed by IVF / ICSI. 


\subsection{Assessments}

All patients had their height and weight measured at time of cycle start. BMI was determined by the ratio of weight (in kilograms) divided by the squared of height (in meters). The patients' age, duration of infertility, anti-Mullerian hormone (AMH) level, antral follicle count (AFC), baseline serum FSH, LH, estradiol (E2), testosterone (T) and progesterone $(\mathrm{P})$ level were collected. The parameters related to the ovarian responsiveness to gonadotrophin stimulation and cycle characteristics (such as the gonadotrophin dose, duration of stimulation, sex hormone levels (estradiol and progesterone levels) on the day of HCG administration, the number of oocytes retrieved, the number of transferred embryos), and pregnancy outcomes including clinical pregnancy rate, spontaneous abortion rate and live birth rate were compared among BMI subgroups.

\subsection{Statistical analyses}

Continuous data were summarized as mean and standard deviation (SD), while categorical variables summarized as n (\%). Statistical analysis was performed using the Statistical Package for Social Science software (SPSS 21.0, Chicago, IL, USA). Differences between continuous variables were analyzed with One-way analysis of variance (ANOVA) test, and the Student-Newman-Keuls (SNK) test was used to analyze post-hoc comparisons; categorical variables were compared using $\chi \square$ tests and logistic regression was used to calculate the ORs and 95\% CI. $P<0.05$ were considered to be statistical significant.

\section{Results}

\subsection{Population characteristics}

In total, 5279 patients under 35 years old undergoing their first IVF / ICSI cycle with fresh, autologous embryos were subjected to analysis. Among the 5279 patients, 728 (13.79\%) were considered underweight, 3650 (69.14\%) normalweight, 735 (13.92\%) overweight, and 166 (3.14\%) obese.

The general characteristics and biochemical test of all patients according to the BMI categories are detailed in Table 1. Compared with the normal-weight patients, the obese patients had the bigger body surface area (BSA), increased AFC and decreased baseline serum FSH, LH level, while the overweight patients had the older age, bigger BSA and decreased baseline serum FSH and LH level $(P<0.05)$. The underweight patients had the younger age, increased baseline serum FSH, LH level compared with the normal-weight $(P<0.05)$. There were no significant differences in the infertility duration, baseline serum testosterone, progestogen level of the patients among the BMI categories.

Table 1 Demographic data and biochemical tests of patients by BMI category 


\begin{tabular}{lccccc}
\hline Variables & $\begin{array}{c}\text { Underweight } \\
(\mathrm{N}=728)\end{array}$ & $\begin{array}{c}\text { Normal-weight } \\
(\mathrm{N}=3650)\end{array}$ & $\begin{array}{c}\text { Overweight } \\
(\mathrm{N}=735)\end{array}$ & $\begin{array}{c}\text { Obesity } \\
(\mathrm{N}=166)\end{array}$ & $\begin{array}{c}\text { Total } \\
(\mathrm{N}=5279)\end{array}$ \\
\hline Years of infertility & $3.64 \pm 2.23$ & $3.83 \pm 2.48$ & $4.01 \pm 2.66$ & $4.65 \pm 2.76$ & $3.85 \pm 2.49$ \\
\hline Women's age (year) \#\# & $28.88 \pm 3.05^{*}$ & $29.75 \pm 2.88$ & $30.34 \pm 2.78^{*}$ & $30.07 \pm 2.90$ & $29.72 \pm 2.92$ \\
\hline BMI (kg/m2) \#\# & $17.62 \pm 0.70^{*}$ & $20.89 \pm 1.44$ & $25.51 \pm 1.11^{*}$ & $30.13 \pm 2.22^{*}$ & $21.37 \pm 2.96$ \\
\hline BSA (m ${ }^{2}$ \#\# & $1.51 \pm 0.06^{*}$ & $1.61 \pm 0.08$ & $1.75 \pm 0.09^{*}$ & $1.89 \pm 0.12^{*}$ & $1.62 \pm 0.11$ \\
\hline Baseline FSH (U/L) \#\# & $5.99 \pm 1.61^{*}$ & $5.59 \pm 1.78$ & $5.18 \pm 1.40^{*}$ & $5.10 \pm 1.45^{*}$ & $5.57 \pm 1.71$ \\
\hline Baseline LH (U/L) \#\# & $4.11 \pm 1.82^{*}$ & $3.54 \pm 2.03$ & $3.01 \pm 1.64^{*}$ & $2.85 \pm 1.80^{*}$ & $3.52 \pm 1.97$ \\
\hline Baseline E2 (pmol/L) \#\# \#\#\#\#\#\#\# $150.07 \pm 70.87$ & $139.79 \pm 120.40$ & $123.06 \pm 99.12$ & $130.98 \pm 83.04$ & $138.61 \pm 111.12$ \\
\hline Baseline T (nmol/L) & $1.75 \pm 6.48$ & $1.91 \pm 7.93$ & $1.66 \pm 2.28$ & $1.64 \pm 0.94$ & $1.85 \pm 7.07$ \\
\hline Baseline P (nmol/L) & $1.60 \pm 5.03$ & $1.15 \pm 2.72$ & $1.02 \pm 1.45$ & $0.83 \pm 0.42$ & $1.18 \pm 2.98$ \\
\hline AMH (ng/ml) \# & $3.99 \pm 3.06$ & $3.89 \pm 2.69$ & $3.55 \pm 2.52$ & $3.62 \pm 2.60$ & $3.84 \pm 2.72$ \\
\hline AFC \#\# & $14.56 \pm 4.39$ & $15.30 \pm 4.92$ & $16.05 \pm 5.51$ & $18.25 \pm 6.38^{*}$ & $15.39 \pm 5.03$ \\
\hline
\end{tabular}

$\mathrm{BMI}=$ body mass index; BSA = body surface area; FSH = follicle stimulating hormone; $\mathrm{LH}=$ luteinizing hormone; $\mathrm{E} 2=$ estradiol; $\mathrm{T}=$ testosterone; $\mathrm{P}=$ progestogen; $\mathrm{AMH}=$ anti-Mullerian hormone; $\mathrm{AFC}=$ Antral follicle count;

Data are shown as the means \pm standard;

${ }^{\#} P<0.05,{ }^{\# \#} P<0.001$, significantly different across the four BMI categories;

${ }^{*} P<0.05$, compared with normal-weight group.

\subsection{IVF / ICSI treatment cycle characteristics}

Regarding the response to the ovarian stimulation and cycle characteristics, we found that the overweight and obese women required more priming gonadotropin dose, total gonadotropin dose, administered dosage per unit of BSA and longer duration of stimulation compared with the patients with normal-weight $(P<0.05)$. On the other hand, we also found that the overweight and obese women had lower serum progestogen and estradiol on the day of HCG administration, lower increased of increase of E2, lower increase of E2 per unit of drug use and lower ovarian sensitivity index (OSI) compared with normal-weight patients $(P<0.05)$. In addition, requirement for less gonadotropin dose and shorter stimulation duration $(P<0.05)$ were found in the underweight infertile patients, with other variables were not significantly different $(P>0.05)$ (Table 2$)$.

There were no significant differences in the number of oocyte retrieved, endometrial thickness on the day of HCG, high quality embryos rate, IVF-fertility rate, ICSI-fertility rate and the number of transferred embryos between the groups (Table 2).

Table 2 Characteristics of IVF / ICSI treatment by BMI category 


\begin{tabular}{|c|c|c|c|c|c|}
\hline Variable & $\begin{array}{l}\text { Underweight } \\
(\mathrm{N}=728)\end{array}$ & $\begin{array}{l}\text { Normal-weight } \\
\qquad(\mathrm{N}=3650)\end{array}$ & $\begin{array}{l}\text { Overweight } \\
(\mathrm{N}=735)\end{array}$ & $\begin{array}{c}\text { Obesity } \\
(\mathrm{N}=166)\end{array}$ & $\begin{array}{c}\text { Total } \\
(\mathrm{N}=5279)\end{array}$ \\
\hline $\begin{array}{l}\text { Gonadotropin } \\
\text { dose (IU) }\end{array}$ & & & & & \\
\hline $\begin{array}{l}\text { Priming for } \\
\text { cycle \#\# }\end{array}$ & $154.81 \pm 48.95^{*}$ & $166.59 \pm 49.46$ & $181.34 \pm 51.23^{*}$ & $191.42 \pm 54.32^{*}$ & $167.80 \pm 50.45$ \\
\hline $\begin{array}{l}\text { Total for } \\
\text { cycle \#\# }\end{array}$ & $2189.60 \pm 801.50^{*}$ & $2397.08 \pm 848.81$ & $2779.17 \pm 933.81^{*}$ & $3118.22 \pm 1053.12^{*}$ & $2444.34 \pm 884.83$ \\
\hline $\begin{array}{l}\text { Duration of } \\
\text { stimulation } \\
\text { (days) } \# \#\end{array}$ & $12.39 \pm 1.73$ & $12.50 \pm 1.97$ & $13.04 \pm 2.48^{*}$ & $13.28 \pm 2.65^{*}$ & $12.59 \pm 2.06$ \\
\hline $\begin{array}{l}\text { The day of HCG } \\
\text { administration }\end{array}$ & & & & & \\
\hline $\begin{array}{c}\mathrm{P} \\
(\mathrm{nmol} / \mathrm{L}) \# \#\end{array}$ & $2.39 \pm 1.01$ & $2.30 \pm 1.02$ & $2.12 \pm 0.95^{*}$ & $1.93 \pm 0.83^{*}$ & $2.27 \pm 1.01$ \\
\hline $\begin{array}{c}\mathrm{E} 2 \\
(\mathrm{pmol} / \mathrm{L})\end{array}$ & $11909.57 \pm 4097.27$ & $11357.90 \pm 5293.88$ & $9904.67 \pm 3879.56^{*}$ & $9223.48 \pm 4240.02^{*}$ & $11164.53 \pm 4978.45$ \\
\hline $\begin{array}{l}\text { Number of } \\
\text { follicles }>16 \\
\mathrm{~mm} \text { in } \\
\text { diameter } \#\end{array}$ & $3.50 \pm 3.76$ & $3.88 \pm 3.95$ & $4.05 \pm 4.01$ & $4.04 \pm 4.09$ & $3.86 \pm 3.94$ \\
\hline $\begin{array}{l}\text { Endometrial } \\
\text { thickness (mm) }\end{array}$ & $10.73 \pm 1.98$ & $10.88 \pm 1.93$ & $10.82 \pm 2.01$ & $10.58 \pm 2.09$ & $10.84 \pm 1.95$ \\
\hline $\begin{array}{l}\text { Administered } \\
\text { dosage per unit } \\
\text { BSA (IU/m } \square) ~ \# \#\end{array}$ & $1452.05 \pm 531.63$ & $1489.53 \pm 526.62$ & $1588.73 \pm 530.46^{*}$ & $1650.48 \pm 541.71^{*}$ & $1503.23 \pm 530.25$ \\
\hline The increased of & $11939.69 \pm 4172.69$ & $11354.88 \pm 5440.85$ & $9819.43 \pm 3891.13^{*}$ & $8975.26 \pm 4301.26^{*}$ & $11152.27 \pm 5108.47$ \\
\hline $\begin{array}{l}\text { Increase of E2 } \\
\text { per unit of drug } \\
\text { use }[(\mathrm{pmol} / \mathrm{L}) / \mathrm{IU}] \\
\# \#\end{array}$ & $6.39 \pm 3.56^{*}$ & $5.49 \pm 3.45$ & $3.98 \pm 2.33^{*}$ & $3.32 \pm 2.19^{*}$ & $5.34 \pm 3.39$ \\
\hline $\begin{array}{l}\text { Number of } \\
\text { oocytes retrieved }\end{array}$ & $11.48 \pm 4.94$ & $11.56 \pm 4.81$ & $11.25 \pm 4.56$ & $10.81 \pm 4.65$ & $11.48 \pm 4.79$ \\
\hline $\begin{array}{l}\text { ovarian } \\
\text { sensitivity index } \\
\text { (OSI) \#\# }\end{array}$ & $6.16 \pm 3.81^{*}$ & $5.63 \pm 3.44$ & $4.59 \pm 2.69^{*}$ & $3.95 \pm 2.47^{*}$ & $5.50 \pm 3.41$ \\
\hline $\begin{array}{l}\text { High quality } \\
\text { embryos (\%) }\end{array}$ & $45.10 \pm 29.65$ & $43.66 \pm 29.87$ & $43.87 \pm 28.77$ & $41.38 \pm 28.84$ & $43.82 \pm 29.66$ \\
\hline $\begin{array}{l}\text { IVF-fertility rate } \\
(\%)\end{array}$ & $82.14 \pm 17.85$ & $82.65 \pm 18.44$ & $82.97 \pm 18.63$ & $83.25 \pm 15.75$ & $82.65 \pm 18.31$ \\
\hline $\begin{array}{l}\text { ICSI- fertility } \\
\text { rate }(\%)\end{array}$ & $64.13 \pm 20.53$ & $62.63 \pm 19.31$ & $62.15 \pm 21.09$ & $66.85 \pm 23.61$ & $62.95 \pm 19.89$ \\
\hline $\begin{array}{l}\text { Number of } \\
\text { transferred } \\
\text { embryos }\end{array}$ & $1.91 \pm 0.29$ & $1.92 \pm 0.27$ & $1.93 \pm 0.25$ & $1.93 \pm 0.26$ & $1.92 \pm 0.27$ \\
\hline
\end{tabular}

HCG = human chorionic gonadotropin; $\mathrm{P}$ = progestogen; E2 = estradiol; $\mathrm{BSA}$ = body surface area;

Data are shown as the means \pm standard; 
${ }^{\#} P<0.05,{ }^{\# \#} P<0.001$, significantly different across the four BMI categories;

${ }^{*} P<0.05$, compared with normal-weight group.

\subsection{IVF / ICSI treatment outcomes}

We analyzed the effects of BMI on pregnancy outcomes of IVF / ICSI. As shown in Table 3, the overweight and obese patients had the higher spontaneous abortion rate than normal-weight women $(13.59 \%$ vs. $10.28 \%$, OR = 1.40, $95 \%$ CI: $1.02-1,90, P=0.036 ; 17.58 \%$ vs.10.28\%, OR $=1.92,95 \%$ CI: $1.09-3.36, P=0.023$, respectively), whereas underweight patients had a similar risk of spontaneous abortion. Compared with normal-weight patients, overweight and obese women seemed to have lower clinical pregnancy rate and live birth rate, but the difference was not statistically significant $(P>$ 0.05).

Table 3 Pregnancy outcomes of IVF / ICSI treatment by BMI category

\begin{tabular}{|c|c|c|c|c|}
\hline variable & $\begin{array}{l}\text { Underweight } \\
(\mathrm{N}=728)\end{array}$ & $\begin{array}{l}\text { Normal-weight } \\
(\mathrm{N}=3650)\end{array}$ & $\begin{array}{l}\text { Overweight } \\
(\mathrm{N}=735)\end{array}$ & $\begin{array}{c}\text { Obesity } \\
(\mathrm{N}=166)\end{array}$ \\
\hline Clinical pregnancy rate & $462(63.46 \%)$ & $2227(61.01 \%)$ & $434(59.05 \%)$ & $91(54.82 \%)$ \\
\hline OR $(95 \% \text { CI })^{\mathrm{a}}$ & $1.14(0.96,1.35)$ & Ref. & $0.91(0.77,1.07)$ & $0.75(0.55,1.04)$ \\
\hline$P$-value ${ }^{\mathrm{a}}$ & 0.131 & & 0.265 & 0.084 \\
\hline Spontaneous abortion rate & $42(9.09 \%)$ & $229(10.28 \%)$ & $59(13.59 \%)^{\#}$ & $16(17.58 \%)^{\#}$ \\
\hline OR $(95 \% \text { CI })^{\mathrm{a}}$ & $0.86(0.61,1.22)$ & Ref. & $1.40(1.02,1.90)$ & $1.92(1.09,3.36)$ \\
\hline$P$-value ${ }^{\mathrm{a}}$ & 0.398 & & $0.036^{*}$ & $0.023^{*}$ \\
\hline Lived birth rate & $345(47.39 \%)$ & $1623(44.47 \%)$ & $310(42.18 \%)$ & $61(36.75 \%)$ \\
\hline OR $(95 \% \mathrm{CI})^{\mathrm{a}}$ & $1.13(0.96,1.34)$ & Ref. & $0.92(0.78,1.08)$ & $0.73(0.53,1.02)$ \\
\hline$P$-value ${ }^{\mathrm{a}}$ & 0.129 & & 0.305 & 0.063 \\
\hline
\end{tabular}

${ }^{\#} P<0.05$, compared with the normal-weight group;

a OR, $P$-values were from logistic regression analysis after adjusting age, duration of infertility, estradiol on HCG day, progesterone on HCG day, endometrial thickness on HCG day, number of oocytes retrieved, and number of embryos transferred, ${ }^{*} P<0.05$.

\section{Discussion}

Over the recent decades, the effect of BMI on the cycle characteristics and IVF / ICSI outcome of ART has been investigated in numerous studies. As the low success rate of the ART and the increased incidence of overweight / obese, it is still very important to explore the various potential factors associated with ART outcomes. In this retrospective study, we focused on the effect of elevated BMI on the ovarian responsiveness to gonadotrophin stimulation and IVF / ICSI outcomes of a down-regulation long GnRH-a protocol in southern Han Chinese women.

It has been established that both underweight and overweight / obesity influence reproductive function of women[25, 26]. Ovarian reserve reflects the potential of reproduction and had been reported to be associated with success of ART in infertile women[27, 28]. Anti-Mullerian hormone (AMH), crucial for recruitment and selection of follicle development, is gonadotropin independent and more consistent measure of ovarian reserve than other hormones such as FSH or inhibin 
B[29-31]. Previous studies had found a negative relationship between elevated BMI and AMH levels[32, 33]. Obesity possibly has an apoptotic effect on granulosa cells (the origin of AMH production), which can reduce AMH production per follicle and induce atresia of ovarian follicles resulting in reduction of ovarian reserve ${ }^{25}$. In our study, we found that compare with normal weight patients, overweight and obese women seemed to have lower AMH levels, but the difference was not statistically significant.

Higher gonadotropin consumption (both priming and total gonadotropin dose) and longer stimulation duration were observed in the overweight and obese patients, when compared with the normal-weight. In order to exclude the influence of body surface area (BSA), we calculated the administered dosage per unit of BSA and found that the overweight and obese women also had the higher administered dosage per unit of BSA. Similar to our results, requirement for higher dose of gonadotropin and longer ovarian stimulation duration in elevated BMI women were also reported in previous investigations[34, 35]. As the dose of gonadotropin use is usually modified according to the woman's age, BMI, and ovarian reserve markers (such as AMH and AFC), it has been considered that ovarian sensitivity index (OSI; the number of retrieved oocytes $\times 1000$ / total dose of gonadotropin) as a better representation of ovarian responsiveness[36]. Our study found that elevated BMI patients had the lower OSI, which also indicated that raised BMI impaired ovarian responsiveness. Irene et al ${ }^{[37]}$ demonstrated that the inhibitory effect of elevated leptin ( a major secretory product of the white adipose tissue) or the increased clearance of the drugs by the excess of fat tissue might induce gonadotrophin resistance, ultimately affect ovarian response. However, the molecular mechanism still remains unclear and needed to be elucidated in future studies.

Moreover, we found that the elevated BMI patients had the lower serum E2 level on the day of HCG administration, lower increased of E2 and lower increase of E2 per unit of drug use. Our finding are consistent with Rehman et al's[38] study, which also observed the lower E2 level on the HCG administration of obese patients. Increasing concentration of follicles serum E2 can cause endometrium hyperplasia and induce the production of growth factors, specific proteins and the receptors of progesterone[39]. The positive correlation of E2 level on the day of HCG administration and pregnancy rates has been investigated in previous studies[40,41]. However, we did not find a significantly lower clinical pregnancy rate in elevated BMI patients who had a lower E2 level on the HCG administration. Uterine receptivity and embryo quality play an important role in the success of IVF / ICSI and embryo transfer cycles ${ }^{[42]}$. Endometrial thickness is a useful indicator of endometrial receptivity and has become part of standard monitoring during IVF / ICSI treatment ${ }^{38}$. Previous studies have found a significant relationship between endometrial thickness and pregnancy outcome of IVF / ICSI[43-45]. In our present study, we did not find any significant differences in the number of retrieved oocytes, endometrial thickness on the HCG administration, the number of transferred embryos, high quality embryos rate and fertilization rate among BMI groups.

In the analysis of the relationship between elevated BMI and pregnancy outcomes, although a decreasing trend in the clinical pregnancy rate and live birth rate were observed in overweight and obese patients, the differences were not statistically significant. This finding was consistent with previous studies, which reported that raised BMI has no adverse effect on clinical pregnancy rate and live birth rate $20,[35]$. In addition, our finding confirmed the previous investigations of an increased risk of spontaneous abortion in raised BMI women following treatment of ART[19, 46, 47]. The reasons for an increased risk of abortion among overweight / obese women are still not well understood. It has been reported that 
both disorders (such as hyperandrogenemia, insulin resistance or altered leptin levels) share endocrine alterations may be responsible for pregnancy loss[48]. María et al's[49] study reported that leptin might induce the inflammation of placental stromal layer, leading to production of pro-inflammatory cytokines (such as IL-6 and TNF- $\alpha$ by activated macrophages), which might play critical roles in placental damage and dysfunction, ultimately affecting pregnancy outcomes. However, abortion susceptibility could be influenced by the multiple factors, including genetic, immunological, infectious, endocrine and environmental factors, further investigation should be performed.

Our study indicated that raised BMI might impair response of ovarian stimulation (required more gonadotrophin dose and longer stimulation duration, had lower OSI and lower serum E2 level on the day of HCG administration) and increase the spontaneous abortion risk during IVF / ICSI treatment. As the negative effect of overweight / obesity on IVF / ICSI outcomes and the additional economic burden caused by the infertility treatment and pregnancy complications, attaining normal BMI by lifestyle modifications (such as a healthy diet and exercise) before and during the IVF / ICSI treatment should be encouraged whenever possible.

\section{Conclusions}

This study demonstrate that raised BMI might impair ovarian response to gonadotrophin stimulation and increase spontaneous abortion risk, suggesting that elevated BMI might have negative effects on the IVF / ICSI outcomes.

\section{Declarations}

\section{Ethics approval and consent to participate}

This study was carried out in accordance with the Ethics Committee of The Third Affiliated Hospital of Guangzhou Medical University with written informed consent from all subjects. All procedures performed in studies involving human participants were in accordance with the principles of the Declaration of Helsinki. Informed consent was obtained from all participants for being included in the study.

\section{Authors' contributions}

LL contributed to writing of this article and provided all sample of this study. CZ assisted in the analysis and interpretation of the data. YC, WO, WL and YL carried out data collection. LK carried out whole design. All authors aided in the design of the study, the interpretation of the data and the critical revision of the manuscript, and all authors approved the final version to be published.

\section{Availability of data and materials}

The datasets used and analysed during the current study are available from the corresponding author on reasonable request. 
Competing interests

The authors declare that they have no competing interests.

\section{References}

1. Catalano PM, Shankar K: Obesity and pregnancy: mechanisms of short term and long term adverse consequences for mother and child. Bmj 2017, 356:j1.

2. Dai RX, He XJ, Hu CL: Maternal pre-pregnancy obesity and the risk of macrosomia: a meta-analysis. Archives of gynecology and obstetrics 2018, 297(1):139-145.

3. Jia YF, Feng Q, Ge ZY, Guo Y, Zhou F, Zhang KS, Wang XW, Lu WH, Liang XW, Gu YQ: Obesity impairs male fertility through long-term effects on spermatogenesis. BMC urology 2018, 18(1):42.

4. Hu L, Huang X, You C, Li J, Hong K, Li P, Wu Y, Wu Q, Wang Z, Gao R et al: Prevalence of overweight, obesity, abdominal obesity and obesity-related risk factors in southern China. PLoS One 2017, 12(9):e0183934.

5. Gao X, Yan Y, Xiang S, Zeng G, Liu S, Sha T, He Q, Li H, Tan S, Chen C et al: The mutual effect of pre-pregnancy body mass index, waist circumference and gestational weight gain on obesity-related adverse pregnancy outcomes: A birth cohort study. PLoS One 2017, 12(6):e0177418.

6. Dadouch R, Faheim M, Juando-Prats C, Parsons J, D'Souza R, Investigators C: Development of a Core Outcome Set for Studies on Obesity in Pregnant Patients (COSSOPP): a study protocol. Trials 2018, 19(1):655.

7. Moussa HN, Alrais MA, Leon MG, Abbas EL, Sibai BM: Obesity epidemic: impact from preconception to postpartum. Future Science Oa 2016, 2(3):FS0137.

8. Talmor A, Dunphy B: Female obesity and infertility. Best practice \& research Clinical obstetrics \& gynaecology 2015, 29(4):498-506.

9. Chen W, Jiao X, Zhang J, Wang L, Yu X: Vitamin D deficiency and high serum IL-6 concentration as risk factors for tubal factor infertility in Chinese women. Nutrition 2018, 49:24.

10. Orkun T, Carr BR: The impact of bariatric surgery on obesity-related infertility and in vitro fertilization outcomes. Seminars in Reproductive Medicine 2012, 30(06):517-528.

11. Zhou Z, Zheng D, Wu H, Li R, Xu S, Kang Y, Cao Y, Chen X, Zhu Y, Xu S: Epidemiology of infertility in China: a population-based study. Bjog An International Journal of Obstetrics \& Gynaecology 2017, 125(Suppl 2).

12. Xu YJ, Ran LM, Zhai SS, Luo XH, Zhang YY, Zhou ZY, Liu YH, Ren LD, Hong T, Liu R: Evaluation of the efficacy of atosiban in pregnant women with threatened preterm labor associated with assisted reproductive technology. European Review for Medical \& Pharmacological Sciences 2016, 20(9):1881.

13. Kissin DM, Jamieson DJ, Barfield WD: Monitoring health outcomes of assisted reproductive technology. N Engl J Med 2014, 371(1):9193.

14. Chen M, Du J, Zhao J, Lv H, Wang Y, Chen XJ, Zhang J, Hu L, Jin G, Shen H: The sex ratio of singleton and twin delivery offspring in assisted reproductive technology in China. Scientific Reports 2017, 7(1).

15. Sheng Y, Lu G, Liu J, Liang X, Ma Y, Zhang X, Zhang S, Sun Y, Sun Y, Chen W: Effect of body mass index on the outcomes of controlled ovarian hyperstimulation in Chinese women with polycystic ovary syndrome: a multicenter, prospective, observational study. J Assist Reprod Genet 2017, 34(1):1-10.

16. Hsieh $\mathrm{Y}$,., Tsai $\mathrm{H}$,., Chang $\mathrm{C}$, ., Lo H, . Comparison of a single half-dose, long-acting form of gonadotropin-releasing hormone analog (GnRH-a) and a short-acting form of $\mathrm{GnRH}-\mathrm{a}$ for pituitary suppression in a controlled ovarian hyperstimulation program. Fertility \& Sterility 2000, 73(4):817-820.

17. Kawwass JF, Kulkarni AD, Hipp HS, Crawford S, Kissin DM, Jamieson DJ: Extremities of body mass index and their association with pregnancy outcomes in women undergoing in vitro fertilization in the United States. Fertil Steril 2016, 106(7):1742-1750.

18. Caillon H, Fréour T, Bach-Ngohou K, Colombel A, Denis MG, Barrière P, Masson D: Effects of female increased body mass index on in vitro fertilization cycles outcome. Obesity Research \& Clinical Practice 2015, 9(4):382-388.

19. Sarais V, Pagliardini L, Rebonato G, Papaleo E, Candiani M, Viganò P: A Comprehensive Analysis of Body Mass Index Effect onin VitroFertilization Outcomes. Nutrients 2016, 8(3):109. 
20. Ioannis M, Hakan C, Denny S, Neal M, Georgios K, Aydin A: Impact of body mass index on IVF and ICSI outcome: a retrospective study. Reproductive Biomedicine Online 2008, 16(6):778-783.

21. Pan X, Zhong L, Nan L, Wu J, Chen D, Zhu Y, Fan Q: Effects of body mass index on the outcomes of in vitro fertilization in Chinese patients with polycystic ovary syndrome: a retrospective cohort study. Journal of Zhejiang University Science B 2018, 19(6):490-496.

22. Vivian R, Srividya S, Sunkara SK, Sviatlana S, Eugene ON, Tarek ET: Effect of body mass index on IVF treatment outcome: an updated systematic review and meta-analysis. Reproductive Biomedicine Online 2011, 23(4):490-499.

23. Kasum M, Oreskovic S, Cehic E, Lila A, Ejubovic E, Soldo D: The role of female obesity on in vitro fertilization outcomes. Gynecol Endocrinol 2018, 34(3):184-188.

24. Hou X, Lu J, Weng J, Ji L, Shan Z, Liu J, Tian H, Ji Q, Zhu D, Ge J: Impact of waist circumference and body mass index on risk of cardiometabolic disorder and cardiovascular disease in Chinese adults: a national diabetes and metabolic disorders survey. Plos One 2013, 8(3):e57319.

25. Rich-Edwards JW, Donna S, Miriam G, Ellen H, Hunter DJ, Colditz GA, Willett WC, Handan W, Manson JAE: Physical activity, body mass index, and ovulatory disorder infertility. Epidemiology 2002, 13(2):184-190.

26. Jungheim ES, Travieso JL, Hopeman MM: Weighing the impact of obesity on female reproductive function and fertility. Nutrition Reviews 2013, 71(S1):S3-S8.

27. Jamil Z, Fatima SS, Ahmed K, Malik R: Anti-Mullerian Hormone:Above and Beyond Conventional Ovarian Reserve Markers. Disease Markers,2016,(2016-2-10) 2016, 2016(3):1-9.

28. Moslehi N, Shab-Bidar S, Ramezani TF, Mirmiran P, Azizi F: Is ovarian reserve associated with body mass index and obesity in reproductive aged women? A meta-analysis. Menopause-the Journal of the North American Menopause Society 2018, 25(9):1.

29. Cui L, Qin Y, Gao X, Lu J, Geng L, Ding L, Qu Z, Zhang X, Chen ZJ: Antimüllerian hormone: correlation with age and androgenic and metabolic factors in women frombirthto postmenopause. Fertility \& Sterility 2016, 105(2):481-485.e481.

30. Renato F, Jo?Lle T, Lozano DHM, Béatrice D, René F, Jean B: High reproducibility of serum anti-Mullerian hormone measurements suggests a multi-staged follicular secretion and strengthens its role in the assessment of ovarian follicular status. Human Reproduction 2005, 20(4):923-927.

31. Volpe A, Marca AL: The anti-Mullerian hormone as a marker of ovarian reserve. Reproductive Biomedicine Online 2006, 13(11):18-18.

32. Bernardi LA, Carnethon MR, de Chavez PJ, Ikhena DE, Neff LM, Baird DD, Marsh EE: Relationship between obesity and anti-Müllerian hormone in reproductive-aged African American women. Obesity 2017, 25(1):229.

33. Su H, Sammel M, Ew, Lin H, Deblasis T, Gracia C: Body size affects measures of ovarian reserve in late reproductive age women. Menopause-the Journal of the North American Menopause Society 2008, 15(5):857-861.

34. Dan Z, Yimin Z, Huijuan G, Biao Z, Runju Z, Tingting W, Guolian D, Fan Q, Hefeng H, Xiue L: Overweight and obesity negatively affect the outcomes of ovarian stimulation and in vitro fertilisation: a cohort study of 2628 Chinese women. Gynecological Endocrinology 2010 , 26(5):325-332.

35. Ozekinci M, Seven A, Olgan S, Sakinci M, Keskin U, Akar ME, Ceyhan ST, Ergun A: Does obesity have detrimental effects on IVF treatment outcomes? BMC Womens Health 2015, 15:61.

36. Hang WRL, Lee VCY, Ho PC, Ng EHY: Ovarian sensitivity index is a better measure of ovarian responsiveness to gonadotrophin stimulation than the number of oocytes during in-vitro fertilization treatment. Journal of Assisted Reproduction \& Genetics 2014 , 31(2):199.

37. Irene S, Baltagi LM, Damien K, Meeker JD, Petrozza JC: Women, weight, and fertility: the effect of body mass index on the outcome of superovulation/intrauterine insemination cycles. Fertility \& Sterility 2011, 95(3):1042-1047.

38. Rehman R, Hussain Z, Faraz N: Effect of estradiol levels on pregnancy outcome in obese women. Journal of Ayub Medical College Abbottabad Jamc 2012, 24(3-4):3.

39. Phophong P, Ranieri DM, Khadum I, Meo F, Serhal P: Basal 17beta-estradiol did not correlate with ovarian response and in vitro fertilization treatment outcome. Fertility \& Sterility 2000, 74(6):1133-1136.

40. Foroozanfard F, Moraveji SA, Taghavi SA, Karimi F: Association Between Serum Estradiol Level on the Day of hCG Administration and IVF-ICSI Outcome. J Obstet Gynaecol India 2016, 66(3):170-173.

41. Kara M, Kutlu T, Sofuoglu K, Devranoglu B, Cetinkaya T: Association between serum estradiol level on the hCG administration day and IVF-ICSI outcome. Iranian Journal of Reproductive Medicine 2012, 10(1):53-58.

42. Barker MA, Boehnlein LM, Kovacs P, Lindheim SR: Follicular and luteal phase endometrial thickness and echogenic pattern and pregnancy outcome in oocyte donation cycles. Journal of Assisted Reproduction \& Genetics 2009, 26(5):243-249. 
43. Yuan X, Saravelos SH, Wang Q, Xu Y, Li TC, Zhou C: Endometrial thickness as a predictor of pregnancy outcomes in 10787 fresh IVFICSI cycles. Reproductive Biomedicine Online 2016, 33(2):197-205.

44. Senturk LM, C Tamer E: Thin endometrium in assisted reproductive technology. Current Opinion in Obstetrics \& Gynecology 2008, 20(3):221.

45. Annemieke K, Smit JG, Torrance HL, Eijkemans MJC, Ben Willem M, Opmeer BC, Broekmans FJM: Endometrial thickness and pregnancy rates after IVF: a systematic review and meta-analysis. Human Reproduction Update 2014, 20(4):530.

46. Wang JX, Davies MJ, Norman RJ: Obesity increases the risk of spontaneous abortion during infertility treatment. Obes Res 2012, 10(6):551-554.

47. Vivian R, Sviatlana S, Alyaa A, Eugene ON, Virginia B, Yacoub K, Peter B, Tarek ET: Influence of BMI on risk of miscarriage after single blastocyst transfer. Human Reproduction 2011, 26(10):2642-2650.

48. Bellver J: Obesity and the risk of spontaneous abortion after oocyte donation. Fertility and Sterility 2003, 79(5):1136-1140.

49. María Jesús V, Antonio RR, Manuel TS: Roles of leptin in reproduction, pregnancy and polycystic ovary syndrome: consensus knowledge and recent developments. Metabolism Clinical \& Experimental 2015, 64(1):79-91. 